\title{
Violência no ambiente de trabalho da enfermagem e educação para os direitos humanos
}

\author{
Adelita Campos Araujo, M.Sc.*, Ana Clara Corrêa Henning, M.Sc.**, Valéria Lerch Lunardi, D.Sc.**
}

* Enfermeira, Doutoranda em Parasitologia, Professora Assistente I dos Cursos de Enfermagem e Medicina da UCPel, Rio Grande do Sul, **Advogada, Professora Assistente da Anhanguera Educacional Pelotas/RS, Orientadora do Trabalho, ***Professora Associada da Faculdade de Enfermagem e Programa de Pós-Graduação Mestrado e Doutorado em Enfermagem da FURG

\section{Resumo}

Trata-se de uma reflexão acerca da violência no ambiente de trabalho da enfermagem, suas consequências para a saúde do trabalhador e a necessidade da inclusão dos direitos humanos, não apenas no seu processo formativo, mas também nas instituiçôes de saúde nas quais relaçōes de violência entre profissionais, pacientes e familiares se perpetuam. As reflexões apóiam-se na produção bibliográfica, enfocando a violência no trabalho da enfermagem no Brasil e no exterior, suas principais manifestações e consequências, finalizando com a valorização da inserção dos direitos humanos no processo formativo dos enfermeiros e nas instituiçóes de saúde. Em decorrência da vivência desses episódios, os profissionais tornam-se mais receosos em relação ao seu fazer, pelos riscos para sua saúde física e mental, com prejuízos ao cuidado prestado por eles. Urge a necessidade das instituiçôes de saúde e escolas de enfermagem mobilizarem-se na construção de estratégias para fortalecer o profissional ou graduando a enfrentarem situaçóes de violência, reivindicando com seus superiores soluçóes e condiçóes condizentes de trabalho, especialmente através de práticas educativas direcionadas à garantia de direitos humanos.

Palavras-chave: violência, local de trabalho, Enfermagem, violação dos direitos humanos.

\section{Abstract \\ Violence in nursing work environment and human rights education}

This is a reflection about the violence in the nursing work environment, its consequences for worker health and the need for inclusion of human rights, not only in the training process, but also in health institutions in which violent relations between professionals, patients and families are perpetuated. The reflections are supported on literature review, focusing on violence in nursing work, in Brazil and abroad, its main manifestations and consequences, ending with the valuation of the insertion of human rights in the training process of nurses and in health institutions. Professionals who experience these episodes become more fearful in relation to their tasks, increasing risks for physical and mental health, and consequently 
affecting nursing care. There is the need of health institutions and nursing schools to mobilize themselves and make strategies to strengthen the professional or the graduate student to face situations of violence, requesting their superiors for solutions and better work conditions, especially, through educational practices aimed at ensuring human rights.

Key-words: violence, working environment, Nursing, human rights abuse.

\section{Resumen}

\section{Violencia en el lugar de trabajo del personal de enfermería y educación en derechos humanos}

El presente trabajo trata de una reflexión acerca de la violencia en el ambiente de trabajo de enfermería, sus consecuencias para la salud del trabajador y la necesidad de inclusión de los derechos humanos, no solo en su proceso formativo, pero también en las instituciones de salud donde relaciones de violencia entre profesionales, pacientes y familiares se perpetúan. Las reflexiones están basadas en la producción bibliográfica, enfocando la violencia en el trabajo de enfermería en Brasil y exterior, sus principales manifestaciones y consecuencias, finalizando con la valorización de la inserción de los derechos humanos en el proceso formativo de enfermeras en las instituciones de salud. En consecuencia de vivenciar esos episodios, los profesionales se tornan más temerosos en relación a sus tareas, por los riesgos para su salud física y mental, perjudicando la atención a los pacientes. Urge la necesidad de las instituciones de salud y escuelas de Enfermería se movilizaren en la construcción de estrategias para fortalecer el profesional o graduando a enfrentaren situaciones de violencia, reivindicando con sus superiores soluciones y condiciones conducentes de trabajo, especialmente a través de prácticas educativas direccionadas a garantía de derechos humanos.

Palabras-clave: violencia, local de trabajo, Enfermería, violación de los derechos humanos.

\section{Introdução}

Presenciar ou sofrer abusos no desenvolvimento das atividades profissionais, seja ela causada por colegas, pacientes ou seus familiares demonstra que sua dignidade pode estar sendo corrompida e desrespeitada, culminando na desumanização profissional. A humanização dos serviços de assistência à saúde, certamente, tem sido um motivo de grande preocupação por parte das organizaçóes nacionais e internacionais de saúde, o que pode ser constatado mediante apreciação dos movimentos e discussões vigentes neste setor, as quais se intensificaram, principalmente, após o surgimento de uma nova forma de pensar o processo saúde-doença [1].

Nesse sentido, deve-se visualizar não apenas o paciente, mas também o trabalhador como ser humano, plausível de fragilidades, o que pode ocasionar adoecimento, prejudicando o andamento do setor onde atua, causando sobrecarga aos demais e transtornos para a assistência de qualidade. Mostra-se fundamental, portanto, um trabalho voltado para ampliar a aptidáo de aprendizagem, a qualificaçáo permanente do cuidado e a construção de práticas, não apenas técnicas, mas críticas, humanísticas e éticas [2].

Salienta-se que muitas são as publicações acerca dos direitos dos pacientes e a necessidade de respeitá-los, mas a literatura é escassa quando se trata de respeito e direitos humanos para com os profissionais da enfermagem, especialmente enfermeiros. Logo, poderia se questionar por que as instituiçóes de saúde, muitas vezes sabedoras desses problemas também administrativos, não buscam alternativas para minimizar agravos entre seus colaboradores? Nos hospitais, onde o trabalho da enfermagem é bastante exigido e sobrecarregado, vários serviços se fazem presentes e poderiam compor estratégias de ajuda. O serviço de educação continuada, por exemplo, poderia em conjunto com o de psicologia, promover palestras, orientar em relação a importância de respeitar os direitos humanos, o outro, independente de hierarquias existentes e das competências de cada um, esquematizando formulários para apontamentos e relatos de abusos. A Educaçáo Continuada deve ser uma ferramenta para promover o desenvolvimento das pessoas e assegurar a qualidade do atendimento aos clientes, devendo, também, ser voltada para a realidade institucional e necessidades do pessoal [2].

Desta maneira, ao se pensar formas de violências vividas no local de trabalho, deve-se atentar para o esquecimento ou omissáo dos direitos humanos para com o semelhante, o conhecimento e valorização de suas necessidades, o entendimento do fluxo 
da unidade que pode depreciar a todos que ali atuam, e a busca de alternativas que visem o bem estar não somente de clientes, mas dos colaboradores. As atividades desenvolvidas no hospital, por sua vez, estão sujeitas "ao humano, à imprevisibilidade das situaçóes, à particularidade das ocorrências e exigências [...] exige maior atenção para observar, escutar, imaginar e antecipar ajustamentos e adaptaçôes" [3].

No entanto, para discorrer sobre o tema é imprescindível inicialmente, situá-lo: violência no ambiente laboral é conceituada como acidentes em que profissionais são atacados de diferentes formas (ameaças, abusos, agressóes) em circunstâncias associadas ao seu trabalho, abrangendo sua deslocação e retorno a este, desde que abarque intimidaçáo, segurança, saúde e bem-estar [4].

Nesse contexto, sabe-se também que ambientes de trabalho mesmo proporcionando satisfação, realização profissional e humana, podem violentar diariamente seja através do poder disciplinar, ou por episódios peculiares as atividades assistenciais [5]. O local de trabalho propicia uma série de riscos, que podem ser impedidos ou minimizados através de diferenciadas medidas de proteção [6]. Uma possibilidade seria as universidades estarem discutindo na formação, os direitos humanos para com o enfermeiro, o que fará o estudante pensar seu futuro profissional, vislumbrando algumas consequências para sua saúde e como evitar ou ajudar companheiros em situaçóes de violação dos seus direitos, desvencilhando-se, sem causar danos à saúde. O processo educativo na enfermagem visa a constituição de profissionais críticos, reflexivos em seus atos, de modo que possam estabelecer sua realidade interligando teoria e prática [2].

Além disso, as instituiçôes de saúde podem adotar registros e armazenamentos da condição de doença dos seus funcionários, o que ajudaria na elaboração de ações preventivas. A elaboração de açóes preventivas é indispensável, pois a instituiçáo deve preservar o bem estar de pacientes que procuram tratamento digno e auxílio [6]. Para corresponder a tal expectativa talvez seja imprescindível investir no pessoal, disponibilizando-se para suas necessidades, inquietaçóes, percebendo fragilidades para atuar na prevenção de doenças e, possivelmente, na desmotivação para o trabalho.

Para a efetivação de algumas ideias nesse campo, é imperativo saber que "o medo de perda do emprego gera pactos de silêncio e omissáo frente a situaçóes de injustiça, em geral dirigidas aos estratos hierárquicos da base" [7]; por isso, a relevância de estimular o relato por parte dos funcionários de casos de violências vividas ou percebidas. Assim, pretende-se refletir acerca da violência no espaço laboral da enfermagem e a necessidade de educação para os direitos humanos.

\section{A violência no ambiente de trabalho da enfermagem no Brasil}

Nos últimos anos, tem se intensificado discussóes acerca da relação do trabalho, satisfação profissional e suas implicaçóes para a saúde do trabalhador. Essa preocupação se deve ao crescente número de profissionais afastados de suas funçóes, muitas vezes, devido a situaçôes de violência provocadas por pacientes, familiares, médicos e colegas: "O problema da violência no local de trabalho não é uma situação nova e desconhecida, principalmente nas áreas profissionais onde o contato direto com o público e com casos de ansiedade e stress é o normal do dia-a-dia" [8]. Há evidências de que o maior número de delinquências acontece com enfermeiros, médicos e trabalhadores de ambulâncias no atendimento pré-hospitalar [9]. Essas circunstâncias podem não apenas comprometer a atividade e a saúde do sujeito, como sua própria produção. Os modos mais frequentes de violência são agressóes físicas e verbais, repressão, ameaças, no qual o ambiente torna-se hostil, podendo ocasionar efeitos psíquicos e físicos [10].

Ao investigarem o não cumprimento de plantóes ocasionados por doença entre trabalhadores de enfermagem em um hospital universitário, evidenciaram $72,6 \%$ de faltas, ausência esta justificada via laudo médico ou atestado, o que significou 494 faltas com 1.491 dias perdidos de rendimento [11]. Em setembro de 2008, foram concedidos 417,3 mil benefícios, no valor total de $\mathrm{R} \$ 274,2$ milhóes, tendo sido requeridos 664,5 mil benefícios [12].

As intercorrências que ocasionam o afastamento do indivíduo podem ter relação direta ou indireta com a vivência de casos de violência. Violência é o uso da força de maneira proposital, poder como intimidação, seja contra si ou outro indivíduo ou grupo, que tem possibilidade de lesionar, matar, causar prejuízos psíquicos, privaçóes [13].

Nesse âmbito, algumas formas de violência foram evidenciadas num estudo realizado, ao caracterizarem brutalidades ocupacionais a que estavam 
expostos médicos e trabalhadores de enfermagem em um serviço de urgência hospitalar, constatando assédio moral (30\%), agressôes físicas (16,7\%), agressōes verbais $(93,3 \%)$, competição entre colegas $(23 \%)$, maus tratos $(3,3 \%)$, discriminação social $(3,3 \%)$ e roubos $(13,3 \%)$. Esta pesquisa contempla as diferentes maneiras como a violência vem se apresentando nos espaços no setor saúde. São perceptíveis sinais de um ambiente não acolhedor, que predispóe seus componentes a vivenciarem desagrados ao prestar serviços, o que pode impedi-los de refletir e aperfeiçoar o seu fazer, além de contribuir para seu adoecimento [14].

Em nosso país

"algumas pesquisas realizadas [...] buscaram a compreensão do processo saúde-doença vivenciado pelos trabalhadores. Estas pesquisas problematizam a relação trabalho-saúde, colocando no centro da análise o caráter social do processo saúde-doença e a necessidade de entendê-lo na sua articulação com o processo de produção [15]".

Tais vivências reforçam a ideia de pensar maneiras de socorrer essa parcela significativa da sociedade. Vê-se que não há indícios de que escolas de enfermagem e instituiçôes de saúde estejam abordando essa questáo ainda na graduação, ou seja, são profissionais que se mostram despreparados para atuar diante de conflitos, o que acarreta transtornos, enfermidades, fazendo com que cada vez mais as agressóes se instalem e o desrespeito impere, não sendo reconhecidos os direitos humanos do indivíduo, independente da sua ocupação.

No entanto, é necessário que as autoridades e os próprios trabalhadores da saúde (médicos, enfermeiros, psicólogos, fisioterapeutas, técnicos de enfermagem, entre outros) busquem seus direitos e os façam realmente valer. $\mathrm{O}$ respeito é um direito de todos e muito se discute os direitos do paciente, o respeito para com sua condiçáo de vida e saúde, mas o funcionário que cuida desse doente é imêmore. Esse indivíduo tem família, problemas pessoais, de formação e interação, ou seja, tem uma vida fora e dentro do hospital, o que nos faz pensar nas complexidades que vive e as necessidades que permeiam esse viver. Sendo assim, ressalta-se que os direitos humanos são inter-relacionados, indissociáveis, universais e interdependentes [16].
A violência no ambiente de trabalho da enfermagem no exterior: manifestaçóes e consequências

O tema em questão gera divergências e provoca reflexão acerca de possíveis momentos constrangedores pelo qual o empregado pode vir a transitar, necessitando de apoio e opçóes para driblar os sentimentos e reaçóes desagradáveis geradas por tais confrontos: "A violência é um problema social e de saúde pública que ameaça o desenvolvimento dos povos, afeta a qualidade de vida e erosiona o tecido social" [9]. Contudo, para alcançar os objetivos propostos neste estudo, faz-se imprescindível abordar algumas pesquisas desenvolvidas no exterior que evidenciam essa problemática e debater acerca do mote mencionado.

$\mathrm{Na}$ Espanha, em levantamento desenvolvido com 464 trabalhadores de enfermagem, foi constatado que $85 \%$ vivenciaram pelo menos uma vez ao mês alguma situaçáo de violência, $11 \%$ uma vez por semana e $4 \%$ várias vezes por semana [17]. Já em pesquisa desenvolvida no Iraque, verificou-se que profissionais da saúde experenciaram pelo menos 3 vezes ou mais circunstâncias de violência no último ano [18]. Investigando dois departamentos de emergência no sudoeste de Queensland na Austrália, foi constatado que $70 \%$ das violências ocorreram nos últimos 5 meses de trabalho [19]. Da mesma forma, foi identificado em Stockholm na Suécia e Midlands na Inglaterra, que $61 \%$ dos enfermeiros ingleses expuseram-se à violência nos últimos 12 meses se comparado com $59 \%$ dos enfermeiros suecos [20]. Pesquisa realizada na Turquia constatou que $79,4 \%$ sofreram abuso verbal no último ano [21]; enquanto que em Columbia (Missouri-USA), 90\% dos enfermeiros experenciaram abuso verbal uma vez no último ano [22].

Os dados acima apresentam ambientes que podem pôr em risco a saúde de trabalhadores fundamentais na recuperação de enfermos que buscam no tratamento e no cuidado sua cura e/ou bem estar. A atividade laboral pode ser visualizada como fonte de satisfaçáo, mas quando esta rescinde os limites da agressão física e psicológica pode proporcionar danos à saúde [23].

Evidencia-se que:

[...] um espaço de disciplinarização e controle da instituição é um espaço de inscriçẫo dos acontecimentos hospitalares, que embora ofereçam algumas satisfaçóes e favoreça a autorrea- 
lização profissional e humana dos trabalhadores [...] também os violentam cotidianamente pelo poder disciplinar e pelos acontecimentos específicos das atividades assistenciais [5].

Os artigos estudados identificaram ainda as seguintes manifestaçóes de violência vividas por enfermeiros, em diferentes países: raiva abusiva, desdenha, ser ignorado [20,24]; violência física, ameaça de violência, abuso emocional [25], agredir com palavróes, gritar, tapas, empurróes, atirar objetos [19,22,26]; ameaça verbal, comportamento agressivo, pontapés, batidas, uso de objetos ou armas pelo agressor [22].

Os diferentes tipos de agressóes apresentadas revelam a percepção da impossibilidade de controle, talvez por serem tấo distintas as açóes evidenciadas, mas ao mesmo tempo elas aguçam a discussão sobre maneiras de evitar esse fenômeno nas instituiçôes de saúde. A atrocidade é concreta, destrói e é imprecisa, sendo possível encará-la e controlá-la [5]. Esse controle pode dar-se através das percepçóes das gerencias e administraçóes acerca dos problemas existentes na instituição e de imediato pensar iniciativas de melhorar a assistência, aperfeiçoando seu corpo funcional para com o seu fazer e suas relações em equipe.

Nesse sentido, altos níveis de fatores adversos relacionados ao trabalho estáo significativamente associados à alta frequência de diferentes tipos de violência [27]. Sendo assim, reforçam dizendo que muitos enfermeiros aceitam o abuso como "parte do trabalho", ou seja, como algo normal no seu cotidiano profissional [28]. Desilusão, burnout e frustração têm sido alguns sinais de desencanto com a violência presente no dia-a-dia da enfermagem, além de alguns sintomas como: insônia, palpitações cardíacas, cansaço, desordem gastrointestinal, cefaléia, hipertensão e perda de peso [29]. Logo, a equipe de enfermagem precisa receber treinamentos de como lidar com a violência, assim como reconhecer a importância do relato e do suporte pós-incidentes [30].

No que tange a sentimentos e reaçóes expressadas por trabalhadores da enfermagem pósexperiência de violência, incidentes associados a diferentes períodos do dia e motivos desencadeadores de agressividades estáo: raiva, tristeza/magoa, choque/surpresa, vergonha e humilhação [20,21], impotência, medo, vergonha, hostilidade [21], frustração, tentar de clarear algum mal entendido com o médico, pedir ajuda para outros $[18,20]$, náo ter reação, tentar fingir que não havia acontecido, pedir para a pessoa parar, tentar se defender fisicamente, procurar aconselhamento, afastamento compulsório do trabalho após o incidente de violência [18].

Ainda no que se refere ao período do dia em que os incidentes aconteceram: $49 \%$ dos incidentes ocorreram das $13 \mathrm{~h}$ às $18 \mathrm{~h} ; 24,5 \%$ ocorreram das $7 \mathrm{~h}$ às $13 \mathrm{~h}$ e $10,2 \%$ ocorreram das $18 \mathrm{~h}$ às $24 \mathrm{~h}$ [18], à tardinha (37\%), à noite (20\%), de dia (20\%) [19]. Os baixos índices de violência durante a manhã evidenciam, nesse período, a maior circulação ou presença de diretores, supervisores, seguranças, familiares, indivíduos que vão fazer exames, visitar pacientes.

Em relação aos motivos desencadeadores de atos violentos, foi constatada: distorção de informações, críticas, falta de consideraçáo profissional, não respeito ao grau de formação e o tempo de atuação profissional [17], condiçôes na cidade com sistemas náo claros, caos, mudanças governamentais devido à guerra, leitos insuficientes, condição de saúde do paciente ou morte, imagem social negativa dos enfermeiros [18].

Esse panorama sombrio apresentado acerca $\mathrm{da}$ violência no trabalho da enfermagem incita a busca por alternativas, prevenindo seu início, muitas vezes insidioso, reforçando o cuidado em horários específicos.

\section{Educação para os direitos humanos: uma pro- posta para a reduçáo da violência no ambiente laboral da enfermagem}

Os direitos humanos nascem com o homem e consequentemente fazem parte da própria natureza humana. Além disso, sinalizam as condiçóes básicas para uma vida íntegra e dizem respeito a um conjunto de exigências e pronunciados jurídicos superiores aos demais direitos - na falta desses o homem não é hábil a viver, desempenhar e compartilhar plenamente da vida [18].

Desse modo, de acordo com as circunstâncias de violências abordadas anteriormente, vê-se a necessidade de interromper as condições de desumanização percebidas, sendo preciso disponibilizar amparo e atitudes que valorizem o respeito, a importância de cuidar da saúde daqueles que cotidianamente cuidam de doentes.

De acordo com o Artigo I da Declaração Universal dos Direitos Humanos, "todas as pessoas nascem livres e iguais em dignidade e direitos. São dotadas de razão e consciência e devem agir em relação umas às outras com espírito de fraternidade" [31]. A 
dificuldade está em pôr em prática e exigir o cumprimento do que a declaraçáo expóe, pois o problema persiste, seja por lacunas advindas desde a formaçáo do profissional, seja pela desconsideração da saúde desses profissionais pelas instituiçóes empregadoras.

Destaca-se que o reconhecimento e proteção dos direitos humanos resultam de processo histórico longo, que aconteceu de maneira gradual, lenta e que ainda se encontra em fase de estruturação [32].

Logo, para minimizar desumanizaçóes parece ser fundamental visualizar o servidor como um todo, sendo importante: sua remuneração adequada, boas condiçóes de trabalho, mas principalmente seu bem estar no local de atuação. É preciso estar ciente de que as consequências da violência no desempenho de sua funçáo são numerosas, tanto na perspectiva organizacional como individual [33].

Um dado também a considerar é indivíduos, de forma geral, não estão instrumentalizados ou não esperam viver uma situaçáo de ferocidade e quando a vivem, a encaram de forma despreparada, o que gera não apenas absenteísmos, mas indivíduos passivos suscetíveis a novos afrontes. Logo, é preciso auxiliar essas pessoas na escolha de condutas adequadas à ocasião vivida; assim, a demonstração de interesse por parte da empresa é importante, pois demonstra amparo e que comportamentos desrespeitosos náo são permitidos dentro da instituição que preza pelo bem-estar e harmonia.

Essa conduta por parte das chefias fortalece o debate pelos direitos humanos e condiçóes básicas para se manter o ambiente laboral saudável. $\mathrm{O}$ apoio não apenas disponibilizando planos de saúde, mas possuindo na instituição uma equipe (enfermeiro do trabalho, psicólogo, enfermeiro responsável pela educaçáo continuada e assistente social) que possa trabalhar essas questóes no quotidiano do serviço. Ao discutir algumas estratégias para a implementação dos direitos humanos, o corpo empresarial estaria reforçando o que na graduação muito se debate, ou seja, respaldar o cuidado de enfermagem por meio do respeito ao ser humano no âmbito político, moral, econômico, ambiental e ético [34]. Ressalta-se que num processo educativo "junto a adultos no seu ambiente de trabalho ou para o seu trabalho, deve levar em consideraçáo que o ponto de partida da aprendizagem é a experiência adquirida por esses profissionais em sua vida diária e que cada um já vem com uma bagagem específica" [2]. Respeitar opinióes e proporcionar trocas de informação somaria esforços para a redução de insatisfaçóes, estimulando a participaçáo de todos nesse processo de avanço.

\section{Conclusão}

O artigo tratou de uma reflexão acerca da violência no ambiente de trabalho da enfermagem e a importância da educação para os direitos humanos. Ambos são assuntos polêmicos e que exigem cuidado ao serem debatidos. Em contrapartida é evidente a necessidade de discussóes acerca da importância da proteção a saúde do trabalhador em saúde.

Enfocou-se a presença da violência nos ambientes de trabalho da enfermagem, bem como seus tipos, frequência, sentimento dos trabalhadores, causas e horários de ocorrência da violência. Assim, foi possível ratificar o desencadeamento do processo de desumanização do profissional enfermeiro, vislumbrando-se possibilidades de prevenção da violência no ambiente de trabalho a partir da graduação em enfermagem, ou seja, as escolas de enfermagem estarem visibilizando e atentando para a violência no cotidiano da enfermagem, e cogitando mudanças em seu currículo com o objetivo de preparar o futuro enfermeiro para o enfrentamento de situaçóes constrangedoras.

A graduação, por ser responsável em debater com os alunos assuntos como cidadania, respeito ao paciente e seus sentimentos, deveria também incluir direitos humanos para com os enfermeiros em situação de violência, tema esse que, como visto no decorrer do texto, permeia o fazer da enfermagem. A iniciativa auxiliaria o futuro profissional a pensar formas de transitar por essas relaçóes (enfermeiro-colega, enfermeiro-paciente/familiar) de maneira mais harmoniosa sem danos ao paciente e servidores.

Também é imperioso que as instituições de saúde (dirigentes e chefias) encontrem formas de identificar relações de violência, estimulando sua denúncia por parte dos profissionais de enfermagem e, juntamente com uma equipe multiprofissional, elaborar estratégias pedagógicas voltadas à educação para os direitos humanos, objetivando prevenir atrocidades e debater o tema, ressaltando a importância da saúde do funcionário para a empresa.

O referido trabalho também oportunizou perceber a escassez de material acerca da violência no ambiente de trabalho da enfermagem no Brasil, bem como quanto aos direitos humanos relacionados aos profissionais da saúde, o que incita ao desenvolvimento de pesquisas e discussóes acerca desse tema 
em nosso país, visando refletir sobre a saúde do trabalhador em enfermagem e o respeito a seus direitos.

\section{Referências}

1. Shiratori K, CostaTL, Formozo GA, Silva SA. Educaçáo em Saúde como estratégia para garantir a dignidade da pessoa humana. Rev Bras Enferm 2004;57(5):617-9.

2. Silva MF, Conceição FA da, Leite MMJ. Educação continuada: um levantamento de necessidades da equipe de enfermagem. O Mundo da Saúde 2008;32(1):47-55.

3. Silva GM, Seiffert OMLB. Educação continuada em enfermagem: uma proposta metodológica. Rev Bras Enferm 2009;62(3):362-6.

4. Antunes AR. Violência contra profissionais de saúde no local de trabalho - estudo de casos portugueses. In: V Conferencia "Psicologia nos cuidados de saúde Primários- Psicologia, Promoção da Saúde e Prevençáo". Miraflores, 19 e 20 de maio 2004.

5. Costa ALRC. As múltiplas formas de violência no trabalho da enfermagem: o cotidiano de trabalho no setor de emergência e urgência clinica em um hospital público [Tese]. São Paulo: Universidade de São Paulo, Escola de Enfermagem de Ribeirão Preto; 2005.

6. Tassimiro CU. Atribuições da Enfermagem na Saúde do Trabalhador. In: Anais do $2^{\circ}$ seminário nacional de diretrizes para enfermagem na atenção básica em saúde (2009). [citado 2011 Ago 12]. Disponível em URL: http://www.abeneventos.com.br

7. Palacios M, Santos ML, Val MB, Medina MI, Abreu M, Cardoso LS, Pereira BB. Violência no trabalho no setor saúde - Rio de Janeiro - Brasil. Universidade Federal do Rio de Janeiro, Núcleo de Estudos de Saúde Coletiva, Relatório Preliminar de Pesquisa (2001/2002). [citado 2011 Ago 13]. Disponível em URL: http:// www.assediomoral.org

8. Correia AL. Enfermeiros e auxiliares são os mais vulneráveis. [citado 2011 Ago 12]. Disponível em: URL: http://www.srsdocs.com

9. Marziale MHP. Violência no setor saúde. Rev Latinoam Enferm 2004;12(2):217-21.

10. Paixão EPS. Trabalhadores frente à violência ocupacional no setor saúde (Maio, 2011). [citado 2011 Ago 12]. Disponível em URL: http://www.claudialana.com.br

11. Silva DMPP, Marziale MHP. Absenteísmo de trabalhadores de enfermagem em um hospital universitário. Rev Latinoam Enferm 2000;8(5):44-51.

12. Previdência Social. Boletim estatístico da previdência social. [citado 2010 out 03]. Disponível em URL: http://wwwl.previdencia.gov.br/pg_secundarias/previdencia_social_13_05.asp.

13. Organizaçáo Mundial da Saúde (OMS). Relatório Mundial sobre violência e saúde. Genebra: OMS; 2002.

14. Cezar ES, Marziale MHP. Problemas de violência ocupacional em um serviço de urgência hospitalar da cidade de Londrina, Paraná, Brasil. Cad Saúde Pública 2006;22(1):217-21.

15. Sarquis LMM, Cruz EBS, Hausmann M, Felli VEA, Peduzzi M. Uma reflexão sobre a saúde do trabalhador de enfermagem e os avanços da legislação trabalhista. Cogitare Enfermagem 2004;9(1):15-24.
16. Lins BJRJ. Segurança, Estado e Direitos Humanos: algumas reflexôes acerca do direito humano à segurança sob a égide da sociedade ocidental contemporânea. Anais do XIX Encontro Nacional do CONPEDI, Fortaleza-CE, junho 2010 .

17. Fornés-Vives J, Martínez-Abascal MA, García GG. Variables socioprofesionales implicadas en el hostigamiento psicológico en enfermería. Enferm Clin 2008;18(3):127-33.

18. Abualrub RF, Khalifa MF, Habbib MB. Workplace violence among Iraqui hospital nurses. J Nurs Scholarsh 2007;39(3):281-8.

19. Crilly J, Chaboyer W, Creedy D. Violence towards emergency department nurses by patients. Accid Emerg Nurs 2004;12:67-73.

20. Manderino MA, Berkey N. Verbal abuse of staff nurses by physicians. J Prof Nurs 1997;13(1):48-55.

21. Kisa S. Turkish nurses'experiences of verbal abuse at work. Arch Psych Nurs 2008;22(4):200-7.

22. Nolan P, Soares J, Dallender J, Thomsen S, Arnetz B. A comparative study of the experiences of violence of English and Swedish mental health nurses. Int J Nurs Stud 2001;38:419-26.

23. Silva JLL, Melo ECP. Estresse e implicaçôes para o trabalhador de enfermagem. Informe-se em promoção da saúde 2006;2(2):16-8

24. Hesketh KL, Estabrooks CA, Reiner MA, Giovannetti P, Hyndman K. Workplace violence in Alberta and British Columbia hospitals. Health Policy 2003;63:311-21.

25. Roche M, Diers D, Duffield C, Catling-Paull C. Violence toward nurses, the work environment, and patient outcomes. J Nurs Scholarsh 2010;32(1):13-22.

26. Merecz D, Reimer MA, Giovannetti P, Hyndman K, Acorn S. Violence at the workplace- a questionnaire survey of nurses. Eur Psychiatry 2006;21:442-50.

27. Camerino D, Estryn-Behar M, Conway PM, van der Heijden BL, Hasselhorn M. Work-related factors and violence among nursing staff in the European NEXT study: A longitudinal cohort study. Int J Nurs Stud 2008; 45:35-50.

28. Edwards S, Connell CF. Exploring bullying: Implications for nurse educators. Nurse Education in Practice 2007;7:26-35.

29. Bigony L, Lipke TC, Lundberg A, McGraw CA, Paqac GL, Rogers A. Lateral Violence in the perioperative setting. AORN J 2009;89(4):688-96.

30. Landy $\mathrm{H}$. Violence and aggression: how nurses perceive their own and colleagues'risk. Emergency nurse 2005;13(7):12-5

31. Declaração Universal dos Direitos Humanos. Adotada e proclamada pela resolução 217 A (III) da Assembleia Geral das Naçôes Unidas em 10 de dezembro de 1948. [citado 201112 Ago]. Disponível em URL: http:// portal.mj.gov.br

32. Gorczevski C, Tauchen G. Educação em Direitos Humanos: para uma cultura da paz. Revista Educação 2008;31(1):66-74.

33. Alexy EM, Hutchins HA. Workplace violence: a primer for critical care nurses. Crit Care Nurs Clin N Am 2006;18:305-12.

34. Shiratori K, Figueiredo, NM, Teixeira MS. Sentido de Ser Humano: uma base reflexiva para o cuidado de enfermagem. Rev Enferm UERJ 2003;11(2):212-6. 